\title{
PRINCÍPIOS DA METODOLOGIA LEAN APLICADOS EM UMA LINHA DE MANUTENÇÃO EM UMA COMPANHIA AÉREA: UM ESTUDO DE CASO DA AERONAVE (HELICÓPTERO MODELO S-70)
}

\section{ARTIGO ORIGINAL}

ALMEIDA, Rodrigo Tito de ${ }^{1}$, MACHADO, Marcos André2, MACEDO, Amarildo ${ }^{3}$, LUZ, Iremar Bezerra da ${ }^{4}$

ALMEIDA, Rodrigo Tito de. Et al. Princípios da metodologia lean aplicados em uma linha de manutenção em uma companhia aérea: um estudo de caso da aeronave (helicóptero modelo S-70). Revista Científica Multidisciplinar Núcleo do Conhecimento. Ano 06, Ed. 12, Vol. 11, pp. 31-47. Dezembro de 2021. ISSN: 24480959, Link de acesso: https://www.nucleodoconhecimento.com.br/engenhariamecanica/companhia-aerea,

DOI: 10.32749/nucleodoconhecimento.com.br/engenharia-mecanica/companhia-aerea

\section{RESUMO}

A manutenção de aeronaves e seus componentes é uma atividade complexa e que deve ser exercida por órgãos ou empresas competentes, sempre preocupados com a eficiência dos trabalhos executados, a fim de garantir a segurança da atividade aérea. Como maneira de garantir essa eficiência e elevar a segurança na manutenção, uma série de metodologias vêm sendo desenvolvidas e aplicadas no segmento manutenção aeronáutica. Visando otimizar todos os processos envolvidos na linha de manutenção, foi proposto um sequenciamento das tarefas executadas em uma inspeção periódica da aeronave S-70, helicóptero fabricado pela empresa americana Sikorsky Aircraft Corporation, em uma oficina na cidade da Manaus/AM. O

\footnotetext{
${ }^{1}$ Bacharel em Engenharia Mecânica. ORCID: 0003-4807-8555.

2 Bacharel em Engenharia Mecânica. ORCID: 0002-5572-8221.

${ }^{3}$ Bacharel em Engenharia Mecânica. ORCID: 0001-5322-4735.

${ }^{4}$ Orientador. ORCID: 002-8897-9166.
} 
desenvolvimento da metodologia proposta iniciou-se em maio/2019, com uma reunião entre os gestores da oficina, encarregados e os desenvolvedores da metodologia, sendo criado um grupo de estudos a fim de identificar todos os processos, delinear uma sequência eficaz para a realização dos cartões de inspeção e estudar maneiras de otimizar a aplicação dos recursos disponíveis na linha de manutenção. Seguindo essa linha, após a fase de planejamento, a metodologia foi aplicada na versão beta na primeira aeronave, onde foi possível compilar, na prática, todos os obstáculos, visando a melhoria do processo. Após os ajustes necessários, o projeto foi novamente aplicado, em outra aeronave, com a correção dos problemas encontrados na inspeção anterior. Com a aplicação da metodologia proposta foi possível melhorar a alocação dos recursos humanos e materiais, bem como otimizar o tempo de inspeção, reduzindo de uma média histórica de sete meses para apenas três meses, superando as expectativas iniciais.

Palavras-chave: manutenção de aeronaves, sequenciamento de tarefas, eficaz, metodologia.

\section{INTRODUÇÃO}

Após a segunda grande guerra, o mundo passou por uma profunda transformação nas relações entre as nações. Capitaneado pelo Japão, o mundo migrou de uma metodologia de gestão, conhecida como Fordismo, que caracterizava-se pelos grandes estoques de matéria prima e produto final, linhas de produção que trabalhavam independentemente da demanda e centralização de todo processo, para uma nova chamada Toyotismo, que tinha por características a produção sob demanda, assim, dispensando a necessidade de grandes armazéns para estoques, descentralização da cadeia de produção, terceirizando inúmeras partes do processo, e foco na qualidade do produto final.

Assim surgiu a metodologia Lean, ou Toyotismo, sendo fundamentada em um modelo reduzido, enxuto. Ela tem por conceito a otimização de todos os processos, focando em aproveitar ao máximo os recursos disponíveis, evitando desperdícios e 
concentrando-se no que é essencial. O método procura produzir cada vez melhor, reduzindo os recursos necessários ao pleno funcionamento e tempo de execução, incorporando valor ao cliente. Tudo isso é possível através do desenvolvimento de técnicas inovadoras, avaliação de tendências do setor e constante monitoração da concorrência, com a introdução do MASP (Metodologia, Análise e Solução de Problemas), buscando solucionar os gargalos existentes, que impedem o pleno fluxo das atividades, através da implementação de processos mais simples e eficientes. Outro aspecto importante é a adoção de sistemas de gestão que automatize processos. As tecnologias de análise e controle de dados permitem que os gestores possam lidar, de forma mais clara, com ações estratégicas automatizadas, lançando mão cada vez menos de procedimentos manuais, repetitivos, complexos e burocráticos.

Quando se analisa qualquer sistema, além da prevenção, faz-se necessário evitar a reincidência do problema, para que se evite desperdício, bem como na qualificação e aprendizado daqueles que o resolvem. Segundo Sobek e Smalley (2010), é fundamental o desenvolvimento das habilidades em todos os colaboradores, independente do cargo de ocupação. Na década de setenta, foi desenvolvida uma ferramenta chamada TPM, pelo japonês Seiichi Nakajima com o objetivo de elevar ao máximo a eficiência de um processo produtivo através da implementação estruturada de seus oito pilares de sustentação, minimizando falhas, promovendo uma manutenção produtiva e total. Com foco na manutenção de suas máquinas e equipamentos, a TPM também preza pelo envolvimento de todos, criando engajamento, sendo refletido diretamente na produtividade e qualidade do produto. Tudo isso só é possível através de uma mudança de postura e mindset, introduzindo uma nova cultura organizacional com a ferramenta TPM introduzida.

A TPM foi rapidamente integrada ao Lean Manufacturing, junto à sua vasta gama de ferramentas que buscam atender um objetivo comum, que é promover a maior estabilidade possível, condição imprescindível para que o modelo enxuto funcione. Os seus oito pilares são: Manutenção Autônoma, Manutenção Planejada, Manutenção da 
Qualidade, Melhorias Especificas, Controle Inicial, Treinamento, Segurança e Meio Ambiente, TPM Administrativo.

Dentro deste contexto, na linha de manutenção de uma aeronave Sikorsky S-70, o modelo de gestão de processos despadronizados tem-se mostrado ineficiente, havendo grande dificuldade na mensuração e contabilidade das tarefas executadas, visto que o modelo não consegue quantificar as sub tarefas que constituem as tarefas principais, acarretando falta de precisão dos custos de cada fase. A falta de padronização e sequenciamento das tarefas a serem realizadas diariamente gera um desencontro entre as oficinas responsáveis pela execução das tarefas correspondentes a cada sistema da aeronave, criando, assim, gargalos de manutenção, como por exemplo, devido ao compartilhamento de equipamentos de apoio e ferramentas calibráveis. Além disso, existem sub tarefas interdisciplinares, que exigem envolvimento de duas oficinas ou mais, que sem a padronização das ações, tem criado, da mesma forma, gargalos que impactam diretamente no prazo e custo das inspeções.

Segundo Yaman (2008), o propósito de uma linha de produção é aumentar a eficiência do sistema produtivo por intermédio da maximização da relação entre os resultados pretendidos e o custo efetivo da produção.

De acordo Ford (1997), a organização e o sequenciamento das atividades de manutenção são questões importantes que devem ser observadas na atividade de manutenção aeronáutica. Para o autor, embora o manual de manutenção e os cartões de tarefas especificarem os procedimentos a serem seguidos, existe um potencial para a divergência entre os procedimentos em papel e a forma como o trabalho é efetivamente realizado, Machado; Urbina e Eller (2010).

O presente trabalho, justifica-se pela necessidade de padronização e sequenciamento das tarefas a serem realizadas na linha de manutenção preventiva de uma aeronave S-70. O atual modelo de processo de manutenção, não prioriza corretamente as etapas das atividades de cada oficina, gerando um descontrole das tarefas a serem 
executadas em todos os níveis, impossibilitando assim a quantificação de sub tarefas, que constituem grande parte das atividades principais, tornando imprecisos os custos reais de cada fase.

Diante do exposto, esse projeto propõe otimizar os processos envolvidos na linha de manutenção da aeronave S-70 através de um planejamento eficiente, identificando os processos envolvidos na linha de manutenção aeronáutica, desenvolvendo soluções otimizadas, definindo uma sequência eficaz para a realização das tarefas de manutenção, a fim de garantir a máxima eficiência do emprego dos recursos materiais e humanos de ponta-a-ponta no processo de manutenção.

Foi montado um grupo de estudo com propósito de identificar os problemas, propor soluções compatíveis com a realidade da linha de manutenção e testá-las, colhendo os resultados e aplicando as correções necessárias. O grupo definiu o uso do software "MS-PROJECT" como a ferramenta para o sequenciamento e automatização das tarefas de manutenção, sendo o mesmo moldado segundo o formato de "SPRINTS", onde cada sprint corresponde a uma fase e nível de manutenção, tendo como base o manual de inspeções do fabricante.

\section{METODOLOGIA}

\subsection{A PESQUISA}

O presente artigo foi realizado durante o ano de 2019 em uma companhia aérea de Manaus - AM que opera helicópteros modelo S-70 Sirkosky e objetiva-se sob a ótica quantitativa e aplicada, tendo como estrutura a gestão de processos aplicada à linha de manutenção de uma aeronave S-70. Objetificado o estudo, sendo criado um grupo de estudo a fim de analisar os problemas, propor soluções e testar as mudanças.

\subsection{POPULAÇÃO E AMOSTRA}

O grupo foi composto por um mantenedor de cada uma das cinco oficinas, o mais experiente, dois inspetores de manutenção e o chefe de manutenção da linha. 


\subsection{INSTRUMENTOS}

Foi definido, o uso do software "MS-PROJECT" na automatização e quantificação das tarefas de manutenção, tendo como referência a inspeção intermediária denominada "PMI-I".

\subsection{COLETA DE DADOS}

Os dados foram retirados do manual do fabricante "TM 1-2840-248-23\&P e do sistema integrado de gestão e logística da companhia aérea.

\subsection{PROCEDIMENTOS DO ESTUDO}

Foram realizadas cinco reuniões do grupo de estudo, dividindo os trabalhos a serem realizados em "SPRINTS", sendo aplicado o conceito da metodologia Google, com discussão dos resultados nas reuniões subsequentes. Na primeira reunião, foi proposto a cada oficina o levantamento de todos os problemas que historicamente afetavam o fluxo de manutenção, através da óptica empírica, pois não havia um setor de estatística da linha. Adicionalmente, foi solicitado que cada setor fizesse uma relação sequenciada de toda atividade de manutenção que se fazia necessário, mas que não era contemplada pelo plano de manutenção do fabricante da aeronave, a fim de chegar mais próximo possível do esforço de manutenção real.

Com a segunda reunião foi realizado a divisão da inspeção em 6 Sprints, sendo: Sprint 1 - Preparação da aeronave para inspeção, Sprint 2 - Desmontagem da aeronave, Sprint 3 - Grandes Inspeções, Sprint 4 - Inspeções Menores, Sprint 5 - Montagem da Aeronave e Sprint 6 - Checks. Foi realizado o etapeamento do Sprint 1 e 2, de forma a achar o mais eficiente sequenciamento das tarefas e evitar quaisquer gargalos no fluxo das atividades de manutenção.

$\mathrm{Na}$ terceira reunião, foi realizado o etapeamento do sprint 3 que corresponde as tarefas de manutenção que necessitam de muito mais tempo para serem realizadas em relação ao tempo médio. Foi definido também que o período da tarde de todas as 
sextas-feiras não teria manutenção programada, a fim de reservar um tempo para que problemas ou atrasos de cunho administrativo fossem resolvidos.

A quarta reunião foi usada para compilar e processar todas as informações colhidas até o momento com o feedback das partes envolvidas, junto o levantamento da necessidade de ferramentas calibráveis e especiais necessárias e etapeamento dos Sprints 4 e 5.

Na quinta e última reunião, foi realizado o etapeamento do Sprint 6 e compilado todas as informações colhidas nas reuniões anteriores, bem como o feedback de todo o estudo e apresentação de todo o planejamento, pronto para ser executado.

\subsection{LIMITAÇÕES DO ESTUDO}

Necessidade de supervisão diária do planejamento, pois apenas a quantificação das atividades foi automatizada, a supervisão não. Capacidade de adaptabilidade e/ou gerência do supervisor, pois essa gestão é feita através de um rodízio com os próprios mantenedores das oficinas de manutenção. Não foi possível acessar dados históricos com mais de cinco anos, pois não havia registros. Houve dificuldade com a logística e a falta de peças de reposição em tempo hábil, que, somado ao déficit de equipamentos calibráveis, atrapalharam fluxo de desenvolvimento das atividades.

\subsection{ANÁLISE DOS DADOS}

Foi realizado uma análise estatística ao término do primeiro ciclo de inspeção após a implementação da metodologia, a fim de se comparar os resultados de antes e depois.

\section{RESULTADOS E DISCUSSÃO}

Segundo Knapp; Zeratsky e Kowitz (2017), o conceito de Sprint da metodologia Google é muito usada, principalmente em startups, devido a sua agilidade no desenvolvido do projeto. Basicamente, consiste em um fluxo de ações que duram cinco dias, e cada dia corresponde a uma fase de evolução do projeto. Dia um - 
Entenda, Dia dois - Desenhe, Dia três - Decida, dia Quatro - Protótipo e Dia Cinco Teste, conforme protótipo desenhado na figura 1 abaixo. Devido as peculiaridades desta companhia aérea, não foi possível ser realizado em cinco dias, mas foram realizadas cinco reuniões seguindo o padrão da metodologia.

Figura 1: Fluxograma da metodologia Google.

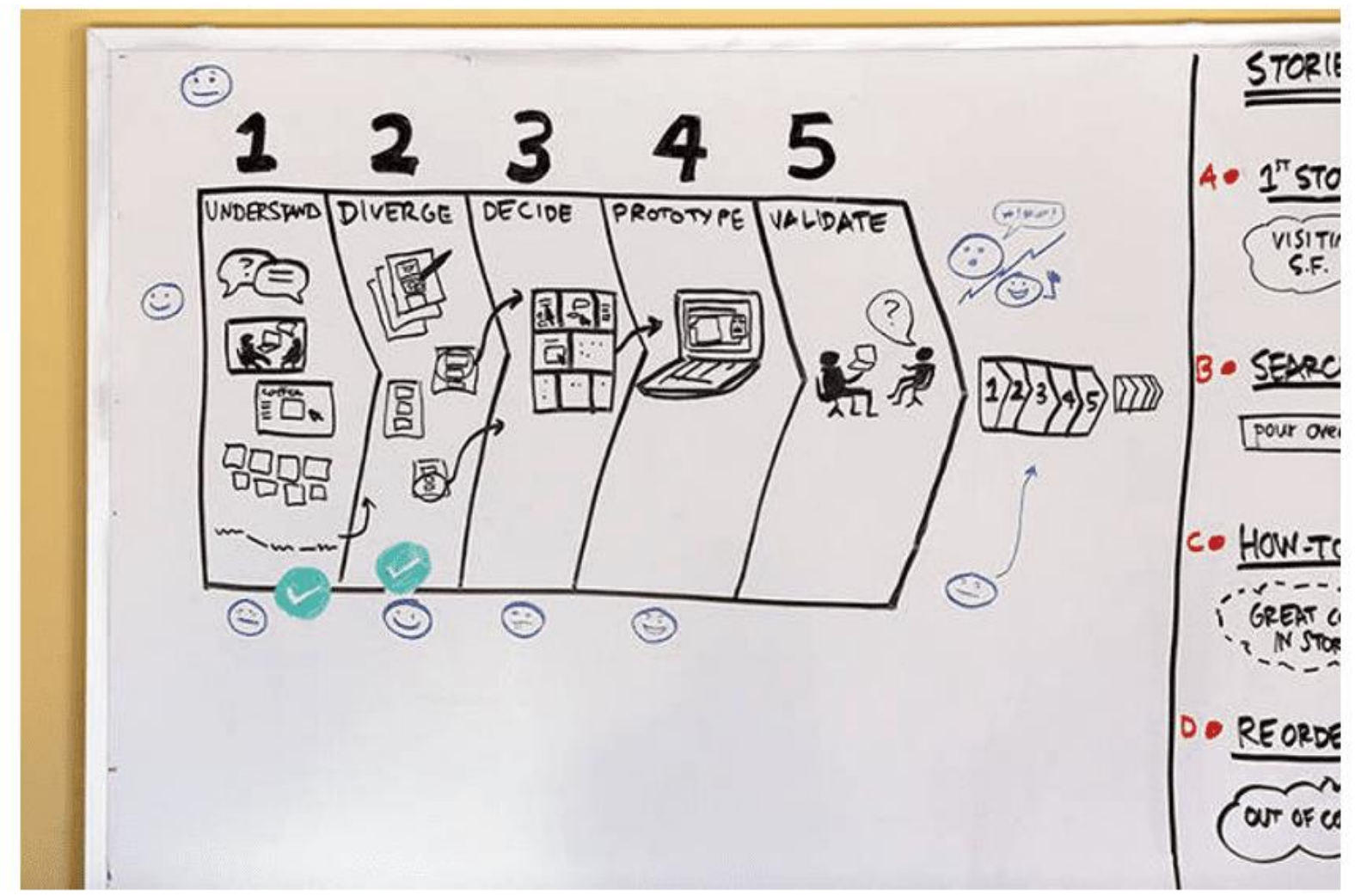

Fonte: Os autores

O protótipo foi todo estruturado no software MS-Project, Oliveira (2005), é divido em seis fases, também chamada de sprints. Cada um dos sprints corresponderam à uma etapa de evolução. O sprint um é a etapa de preparação da aeronave para as atividades de manutenção, onde é feito a remoção das carenagens (fuselagem removível) para uma melhor lavagem. O sprint dois corresponde a etapa de desmontagem dos componentes que serão inspecionados/substituídos pelas oficinas em bancadas de manutenção. A fim de se evitar o efeito descrito pela teoria da lei de Parkinson, o terceiro sprint foi modelado dando prioridade de inspeção para as 
atividades que demandam muito tempo para serem realizadas. A concentração dessas atividades em um período específico deu maior previsibilidade do esforço de mão de obra, definindo o ponto em que há o pico de trabalho, e assim, onde há a maior necessidade de emprego de recurso humano e material. Para o quarto sprint ficaram as demais inspeções, denominada "inspeções menores", ou seja, as que demandavam menos tempo de execução, ou que eram mais simples a serem realizadas. O sprint cinco é a fase de montagem de todos os componentes e carenagens removidos. No sprint seis foi concentrado todos os checks que se fazem necessários após a manutenção de uma série de componentes eletroeletrônicos. Essa concentração fez-se necessário devido os checks serem realizados com equipamentos calibráveis que, na maioria das vezes, ficavam indisponível, seja por panes ou devido alta demanda de uso deles, e concentrando-os em um determinado período, pode-se saber com exatidão o período que tais equipamentos seriam usados.

As figuras abaixo demonstram a estruturação do planejamento de inspeção desenvolvido em sua forma analítica, Figura 2, e em gráfico de Gantt, Figura 3. As atividades de manutenção foram sequenciadas de forma inteligente para garantir um fluxo constante entre uma tarefa e sua predecessora, reduzindo o tempo de execução e os conflitos entre si. 
Figura 2: Modelo da estruturação do software

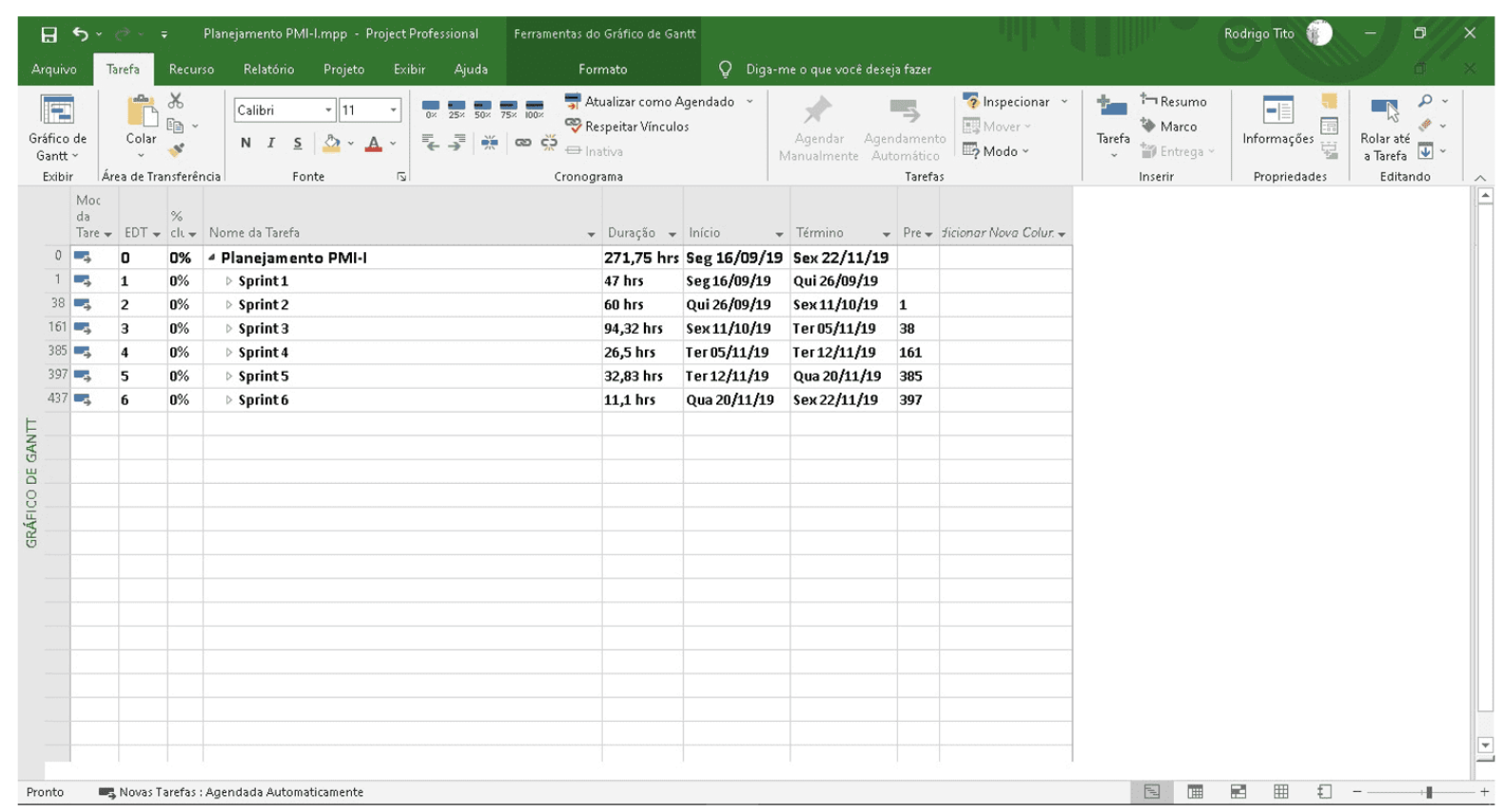

Fonte: Arquivo da chefia da linha de manutenção.

Figura 3: Modelo da estruturação do software em Gráfico de Gantt

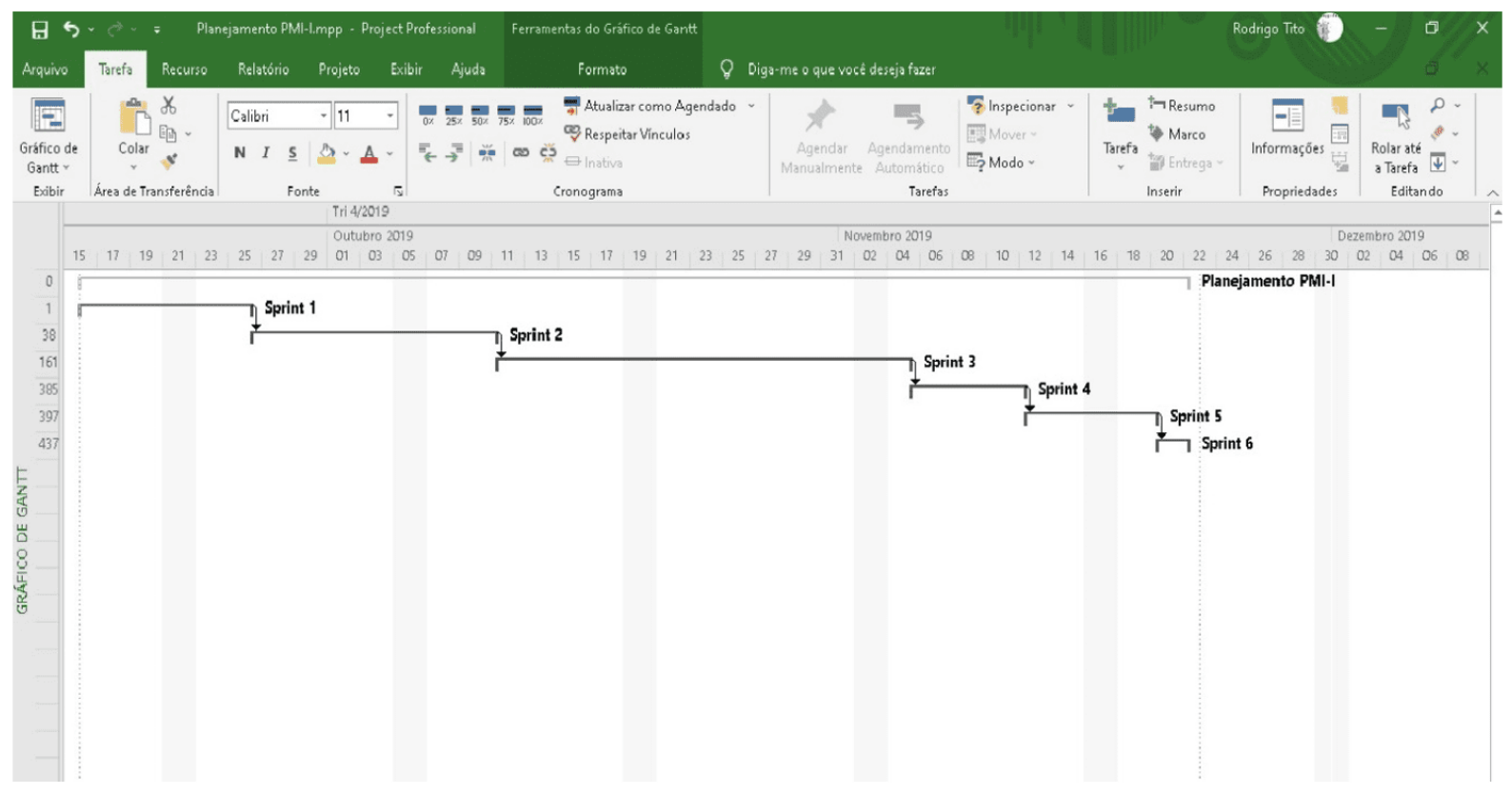

Fonte: Arquivo da chefia da linha de manutenção.

RC: 104088

Disponível em: https://www.nucleodoconhecimento.com.br/engenhariamecanica/companhia-aerea 
As tarefas foram sequenciadas de forma que desse um fluxo eficiente para as atividades, descasando aquelas tarefas que viriam a criar um gargalo, seja por compartilhamento de equipamentos de uso comum, como talhas de içamento, seja por ferramentas calibráveis. Tarefas maiores foram divididas em tarefas menores, chamadas de sub tarefas, dando maior fluidez nas ações e melhor mensuração do progresso da inspeção, conforme a figura abaixo.

Figura 4: Modelo da estruturação do software - Forma Analítica

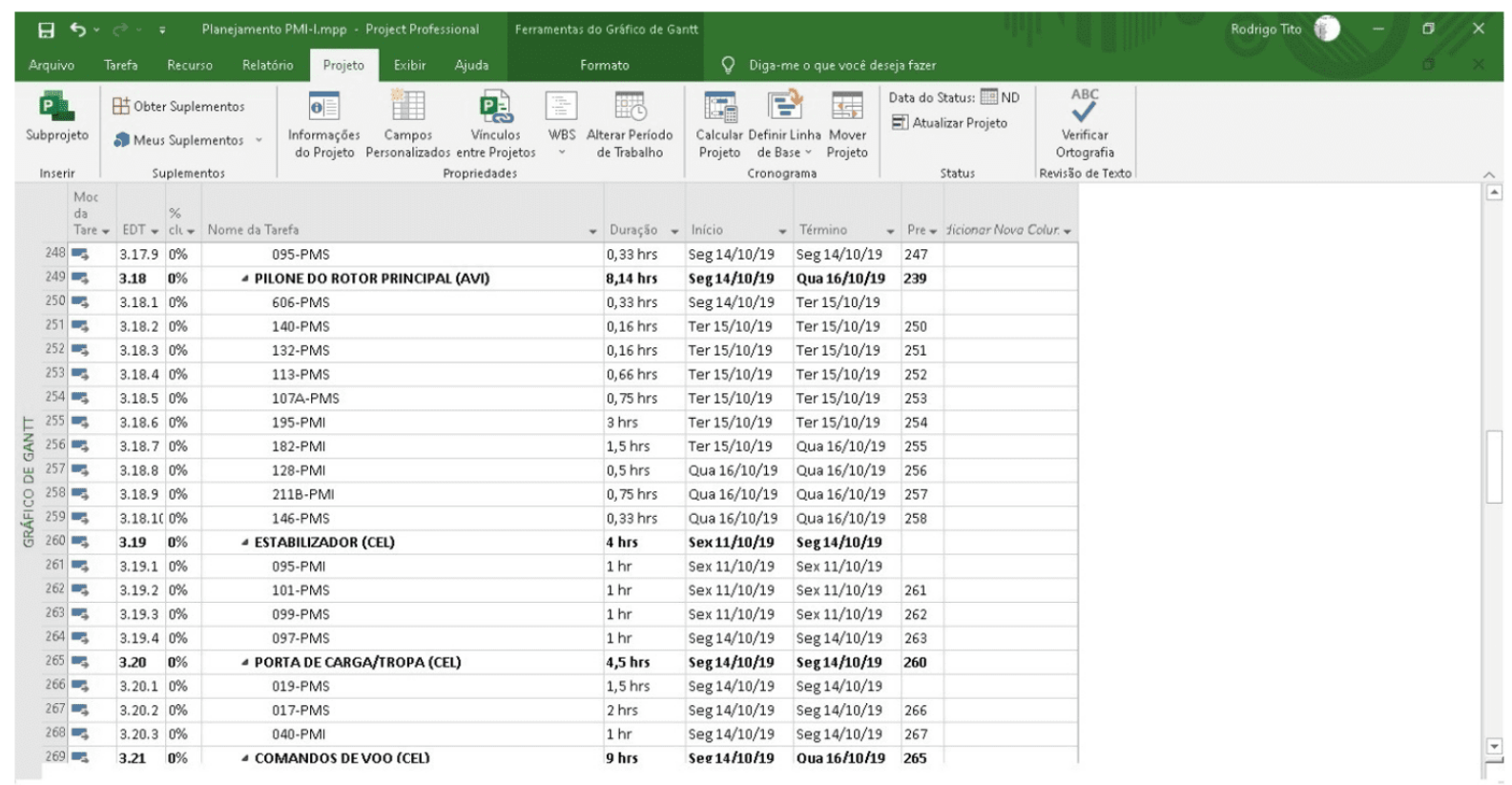

Fonte: Arquivo da chefia da linha de manutenção.

Foi realizado um breafing com os encarregados das oficinas para início do projeto e padronizado que todas as quintas-feiras haveria uma breve reunião para comparação entre o planejado e o executado, propondo ajustes necessários e leitura das atividades da semana seguinte. A primeira ação executada foi a implementação da metodologia de "B.O.M (Bill of Materials)" em todas as oficinas, a fim de atenuar o gargalo do fluxo logístico, dando mais previsibilidade e antecipação dos materiais usados nas tarefas de manutenção. Isso proporcionou saber com antecipação e exatidão todos os materiais necessários e quando seriam necessários nas atividades de inspeção. 
Figura 5: B.O.M - Adaptação

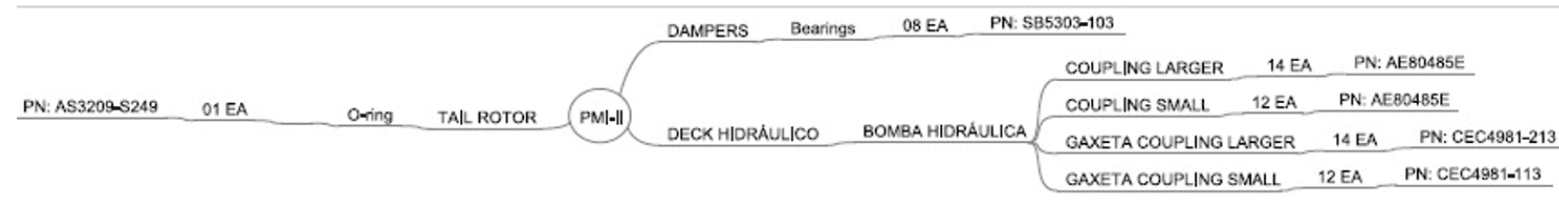

Fonte: Oficina de Hidráulica

Conforme pode ser visto na Figura 5, foi contemplado toda necessidade de material das oficinas necessários para realizar todas as atividades de manutenção sem interrupção dos serviços. O projeto foi testado em duas aeronaves em sequência, sendo realizado nas aeronaves de matrícula S-70 8903 e S-70 8914.

\subsection{AERONAVE S-70 8903}

A inspeção do S- 70, de numeração 8903 , foi planejada para durar dez semanas, na data de 16/09/19 a 22/11/19, onde a evolução foi atualizada semanalmente conforme a tabela abaixo. A Tabela 1 traz um resumo dos acontecimentos durante as dez semanas planejadas para as atividades.

Tabela 1: Resumo

\begin{tabular}{|c|c|}
\hline SEMANA & DESCRIÇÃO \\
\hline UM & Sem atrasos no cronograma. Terminou adiantada em 1p.p. \\
\hline DOIS & $\begin{array}{l}\text { Houve aceleração na realização das atividades. Terminou adiantada em } \\
\text { 15p.p. }\end{array}$ \\
\hline TRÊS & $\begin{array}{l}\text { Produção bem acima do planejado, mas detectado uma tendência de } \\
\text { reversão da curva S. Terminou adiantada em 15p.p. }\end{array}$ \\
\hline QUATRO & $\begin{array}{l}\text { Atraso na entrega de novos equipamentos, o que criou um efeito dominó } \\
\text { em sub tarefas que necessitavam que suas predecessoras fossem } \\
\text { realizadas com o aditivo de um aumento da demanda por mão de obra } \\
\text { em outras frentes de manutenção. Terminou adiantada em } 4 p . p . \text { e com } \\
\text { forte tendência de reversão na curva. }\end{array}$ \\
\hline
\end{tabular}


CINCO Foi impactada pelos problemas logísticos e baixa de mão-de-obra disponível, sendo atenuada pela produção das oficinas que não sofreram atrasos na entrega de material. Primeira semana abaixo do planejado, terminou atrasada em 3p.p.

SEIS Alguns equipamentos começaram a chegar. Foi criado um turno noturno para dar vazão aos materiais que chegavam e estender o horário de trabalho de modo que minimizasse a indisponibilidade de recursos humanos. Terminou com atraso de 7p.p.

SETE Turno noturno mostrou-se eficiente, de forma que o atraso estabilizou. Não houve mudanças significativas com relação à logística. Terminou com atraso de 6p.p.

OITO Houve remanejamento de pessoal de oficinas sem atrasos para oficinas atrasadas, de forma que se mantivesse o caminho crítico sem óbices. Terminou com atraso de 6p.p.

NOVE Fluxo de materiais melhorou, bem como a chegada o equipamento necessário para a realização do teste do sistema de combustível que alimenta os motores. Tal teste deveria ter sido realizado na semana dois e causou o mais impactante efeito dominó. Entretanto, aumentou o índice de indisponibilidade de mão-de-obra devido o início de uma inspeção de outra aeronave em paralelo com esta. Terminou com atraso de 7p.p.

DEZ Chegada do material restante para a conclusão. Foi planejado uma força-tarefa com paralização pontual e toda as demandas extras, a fim de aplicar toda capacidade de recursos humanos disponíveis, juntamente com o turno noturno. Terminou dentro do prazo planejado.

Fonte: Arquivo da chefia da linha de manutenção. p.p. = Pontos Percentuais.

Conforme a Figura 6, podemos acompanhar, traduzido pela curva S, todo o desenvolvimento das atividades agrupado por semana durante o período planejado. É possível observar com clareza o resumo da Tabela 1 e como os óbices impactaram 
os serviços com o decorrer das semanas, bem como a dificuldade em realizar as atividades atrasadas concomitantemente com as programadas para aquela determinada semana.

Figura 6: Curva S

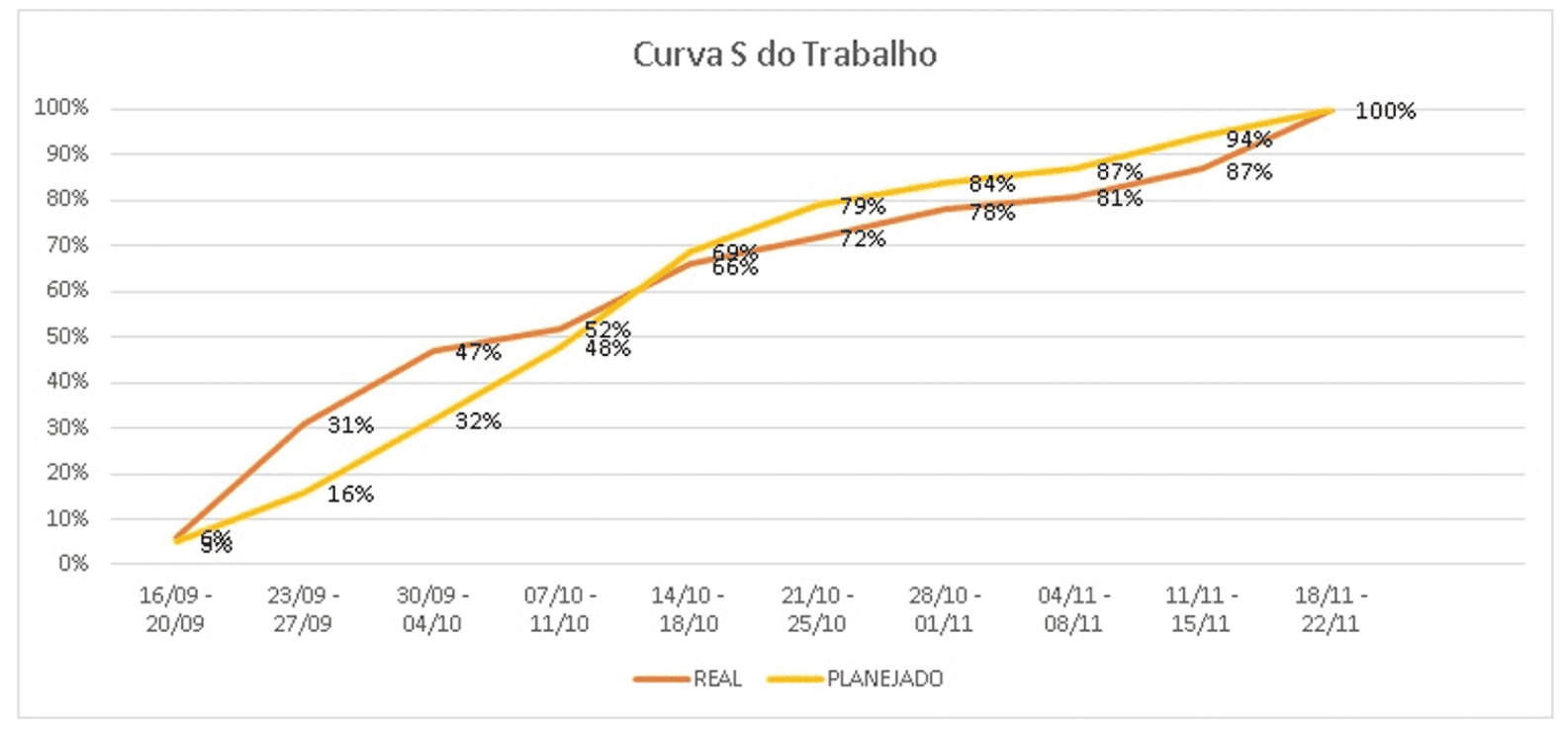

Fonte: Arquivo da chefia da linha de manutenção.

Finalizada a inspeção, foi realizado uma análise dos dados obtidos com a finalidade de entender os óbices e aperfeiçoar os processos. Ficou constatado que houve um superdimensionamento do tempo de execução das tarefas das semanas dois e três, enquanto houve um sub dimensionamento das tarefas das semanas cinco e seis. Foi realizado os ajustes necessários no aspecto tempo de duração. Observou-se também alguns conflitos pontuais na sequência de algumas tarefas, sendo ajustado o seu caminho crítico. Após os ajustes, o planejamento foi novamente testado na aeronave matrícula S-70 8914.

\subsection{S-70 8914}

Devido o início da inspeção ser em uma quinta-feira, a primeira semana teve apenas dois dias de inspeção e a última semana quatro dias, que, somado a paralização de 
duas semanas devido ao recesso de fim de ano, teve a duração de quatorze semanas corridas.

A Tabela 1 traz um resumo dos acontecimentos durante as quatorze semanas planejadas para as atividades.

Tabela 2: Resumo

\begin{tabular}{|c|c|}
\hline SEMANA & DESCRIÇÃO \\
\hline UM & Conforme o planejado, sem óbices. \\
\hline DOIS & $\begin{array}{l}\text { Seguiu de acordo com o planejado, terminou com adiantamento de } \\
\text { 1p.p. }\end{array}$ \\
\hline TRÊS & $\begin{array}{l}\text { Houve imprevistos pontuais, mas sem afetar o caminho crítico. } \\
\text { Manteve o adiantamento de } 1 \text { p.p. }\end{array}$ \\
\hline QUATRO & Sem maiores evoluções, terminou conforme o planejado. \\
\hline CINCO & $\begin{array}{l}\text { Ligeiramente acelerada e sem novos imprevistos. Terminou com } \\
\text { adiantamento de 3p.p. }\end{array}$ \\
\hline SEIS & $\begin{array}{l}\text { Novamente com imprevistos pontuais, conseguiu manter o planejado } \\
\text { para a semana. }\end{array}$ \\
\hline SETE & $\begin{array}{l}\text { Com metade da capacidade devido o recesso de Natal, as atividades } \\
\text { evoluíram mais lentamente. Terminou com atraso de 1p.p. }\end{array}$ \\
\hline OITO & Não houve atividades de manutenção devido o recesso de ano novo. \\
\hline NOVE & $\begin{array}{l}\text { Semana pós recessos, houve aceleração das atividades afim de } \\
\text { compensar a paralisação da semana anterior. Terminou com } \\
\text { adiantamento de 3p.p. }\end{array}$ \\
\hline DEZ & $\begin{array}{l}\text { Seguiu em ritmo cadenciado, sem óbices. Terminou com } \\
\text { adiantamento de 1p.p. }\end{array}$ \\
\hline ONZE & $\begin{array}{l}\text { Conforme o ritmo de semanas anteriores e sem problemas de } \\
\text { aspecto material e humano, terminou com adiantamento de } 2 p . p \text {. }\end{array}$ \\
\hline DOZE & Seguiu conforme planejado, terminando com adiantamento de 3p.p. \\
\hline TREZE & Impactada por uma pane em \\
\hline
\end{tabular}


alimentação de combustível dos motores, as atividades seguiram de forma mais lenta, contudo, a semana terminou sem atrasos no cronograma.

QUATORZE Com a inspeção praticamente finalizada e sem óbices, foi finalizada conforme o planejamento.

Fonte: Arquivo da chefia da linha de manutenção. p.p. = Pontos Percentuais.

$\mathrm{Na}$ Tabela 7, podemos observar que as mudanças feitas após os dados colhidos com a inspeção do S-70 8903 foram precisas com a linha do trabalho REAL quase coincidente com a linha do trabalho Planejado.

Figura 7: Curva S

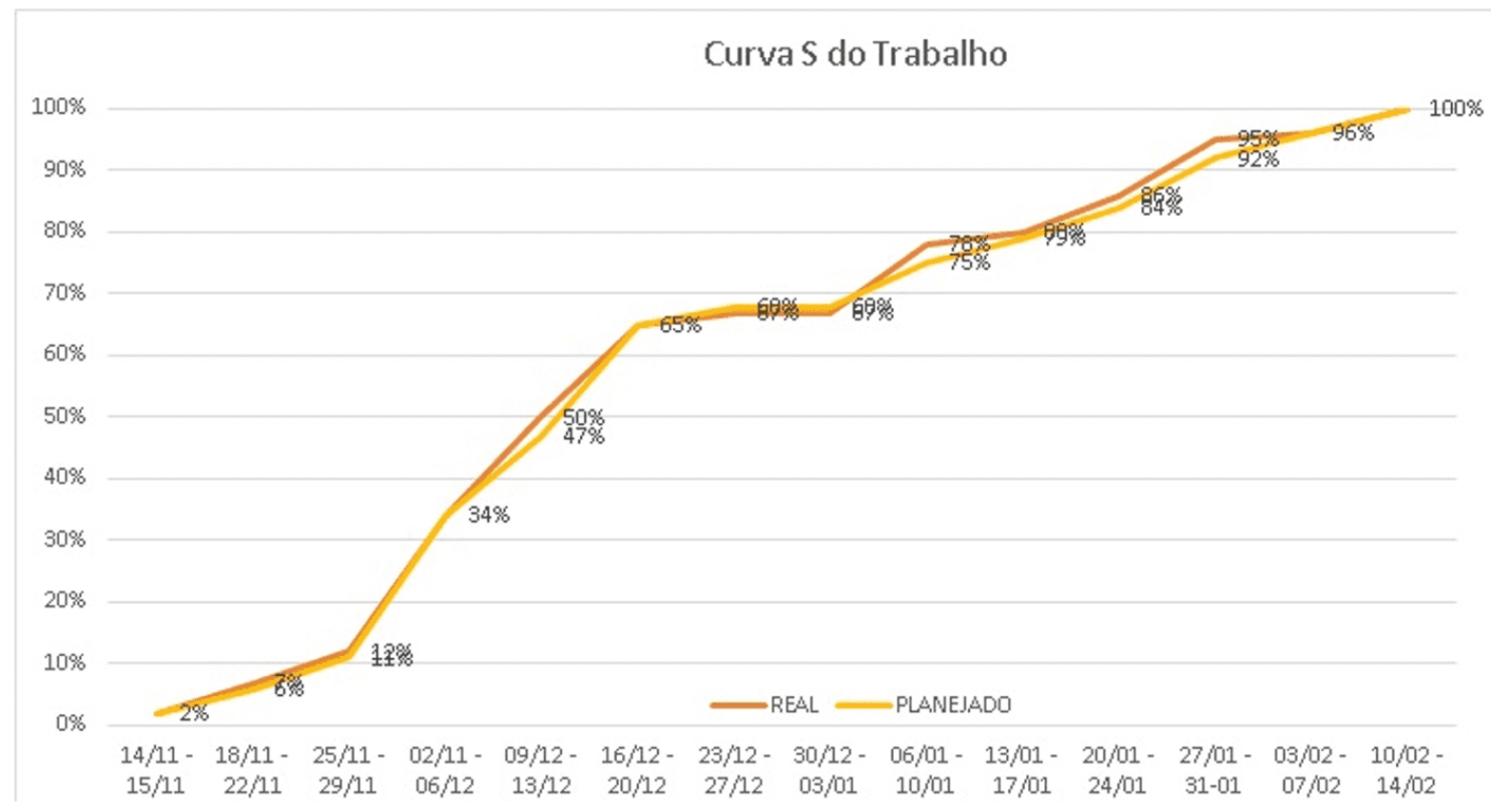

Fonte: Arquivo da chefia da linha de manutenção.

As inspeções das aeronaves S-70 8903 e S-70 8914 foram planejadas para, respectivamente, 50 dias úteis e 59 dias úteis, enquanto o antigo planejamento contabilizava a inspeção em 70 dias úteis. Já a média histórica desta companhia aérea 
era de sete meses por inspeção PMI-I, enquanto com este planejamento, as duas inspeções, juntas, tiveram duração de seis meses.

$\mathrm{Na}$ figura 8 podemos observar a construção do caminho crítico (em rosa), pela linha do tempo. É chamado de crítico por ser a "espinha dorsal" do planejamento correspondendo àquelas tarefas que não possuem margem de atraso, ou seja, atrasam ou adiantam o prazo de toda a inspeção. 
Figura 8: Caminho Crítico

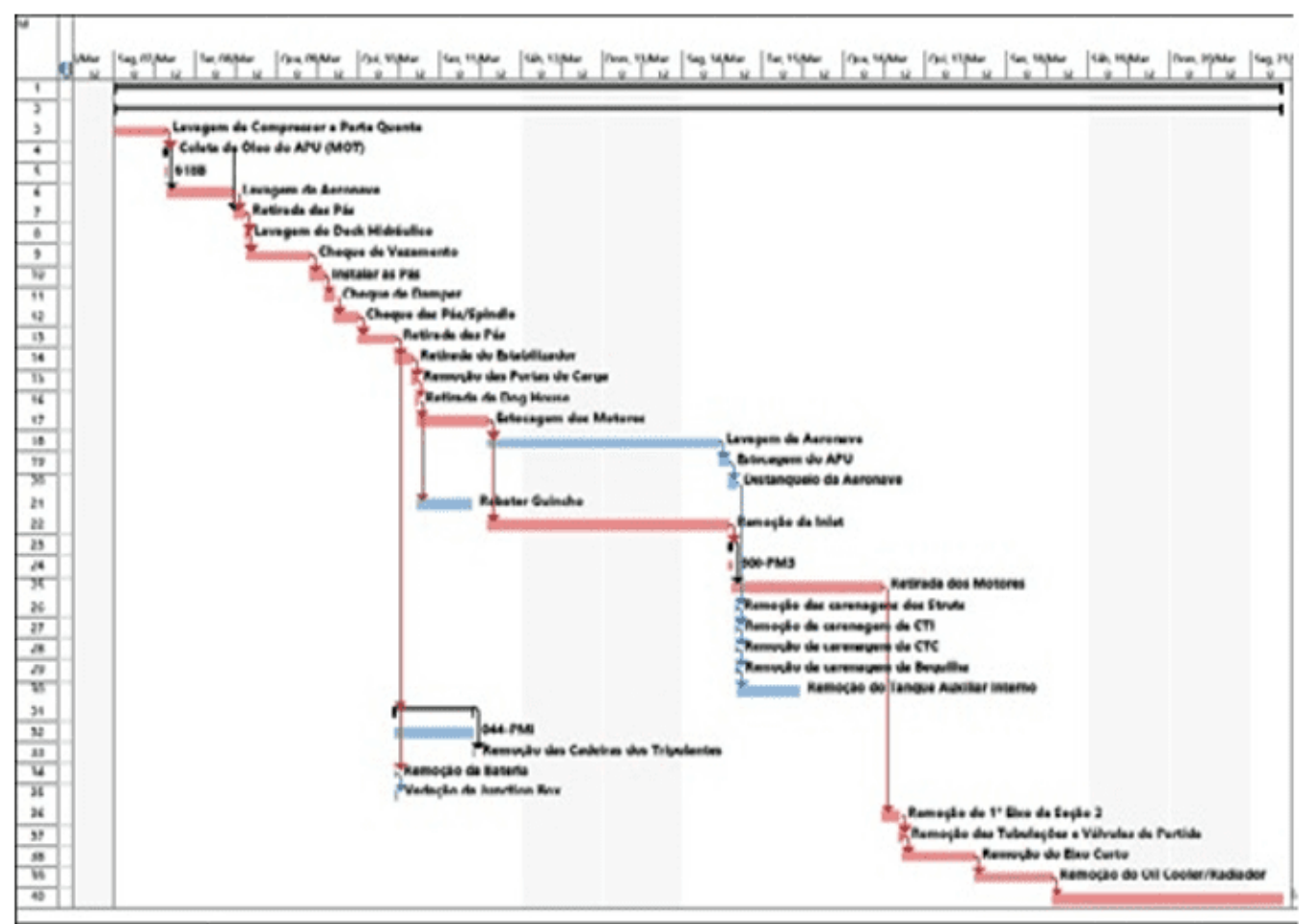

ANTES

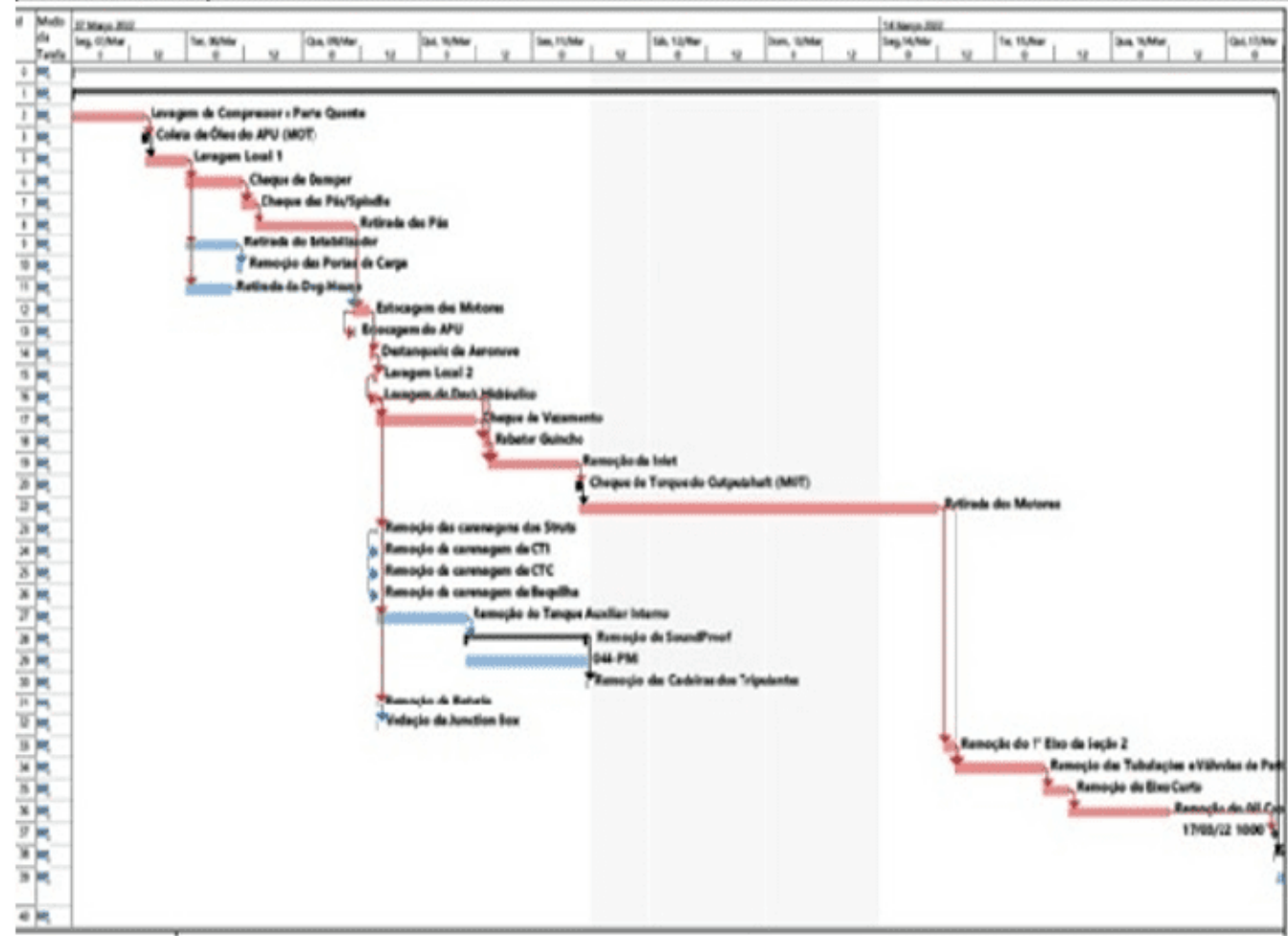

Fonte: Arquivo da chefia da linha de manutenção.

RC: 104088

Disponível em: https://www.nucleodoconhecimento.com.br/engenhariamecanica/companhia-aerea 
Apesar dos óbices encontrados nas inspeções de ambas as aeronaves, houve um enorme esforço para que a realização das tarefas críticas permanecesse em dia, onde mesmo com os atrasos observados, não permitiram que houvesse atraso no cronograma geral planejado.

Foi observado uma economia acima de $60 \%$ do custo geral de inspeção em relação ao modelo de inspeção anterior ao estudo com aumento de eficiência (redução de tempo) em mais de $100 \%$.

\section{CONSIDERAÇÕES FINAIS}

O Projeto claramente atingiu seu objetivo, reduzindo os custos de inspeção, traduzidos na redução do tempo de execução das tarefas em mais de $50 \%$, otimizando o sequenciamento das atividades com emprego eficiente de recursos materiais e humanos. Foi agregado uma nova cultura organizacional na gestão dos processos na linha de manutenção onde todos os envolvidos no processo foram submetidos a uma nova dinâmica de controle e execução.

Em linha com o apresentado, estudos semelhantes com aplicação da metodologia enxuta (metodologia lean) seguem a mesma linha de implementação e execução da metodologia, como é o caso de Bernard (2017), cuja pesquisa trouxe uma clara visão dos benefícios da implementação da metodologia Lean em ambientes hospitalares. Os benefícios envolvem melhorias operacionais na otimização de processos, aumento da satisfação dos pacientes, redução no tempo de espera, aumento na motivação dos colaboradores, redução de custo, engajamento da equipe hospitalar etc. Em Lindgren (2001), o estudo analisa a implementação da metodologia lean, em especial na EMBRAER, empresa brasileira de fabricação de aeronaves. A pesquisa evidencia um robusto e consistente resultado em termos de racionalização dos processos, dos recursos e burocracia. 


\section{REFERÊNCIAS}

BERNARDO, Vítor Zanetti. Melhorias Na Gestão Estratégica Hospitalar Com A Utilização Do Lean Six Sigma: Uma Contribuição Teórica, São Carlos, 2017.

FERREIRA, Renata. Sistemas Lean. Volume 1, Belo Horizonte, 2018.

KNAPP, Jake.; ZERATSKY, John.; KOWITZ, Braden. Sprint - o método usado no google para testar e aplicar novas ideias em apenas cinco dias, Rio de Janeiro, 2017.

LINDGREN, Paulo Cesar Corrêa. Implementação Do Sistema De Manufatura Enxuta (Lean Manufacturing) Na Embraer, Taubaté, 2001.

MARTINS, Gabriel Kazuo Kimura. Implementação De Uma Sistemática Para Resolução De Problemas Na Origem: Um Estudo De Caso Em Uma Empresa Do Segmento De Duas Rodas Do Polo Industrial De Manaus, Manaus, 2020.

MACHADO, Márcio Cardoso.; URBINA, Lígia Maria Soto.; ELLER, Michelle Aparecida Gomes. Planejamento de uma linha de manutenção de aeronaves. Aplicação dos conceitos de balanceamento, São Carlos, 2010.

OLIVEIRA, Guilherme Bueno De. Ms Project \& Gestão De Projetos, São Paulo, 2005.

Enviado: Junho, 2021.

Aprovado: Dezembro, 2021. 